\title{
Baseline survey on functioning of abortion services in government approved CAC centres in three pilot districts of Nepal
}

\author{
Karki C ${ }^{1}$, Ojha $\mathbf{M}^{2}$, Rayamajhi RT $^{3}$ \\ ${ }^{1}$ Associate Professor, ${ }^{3}$ Assistant Professor, Department of Obstetrics and Gynecology, Kathmandu Medical College, \\ ${ }^{2}$ Chief, High Level Committe for implementing medical abortion service, Ministry of Health and Population, Nepal
}

\begin{abstract}
Background: Abortion has been legalized in Nepal since September 2002 and under this law, Comprehensive Abortion Care (CAC) service is being provided through listed service providers and listed health facilities from 2004. Nepal Government has prioritized the national safe abortion program and is working with many government and non government partners for providing this service. Till date medical abortion services are not made available at any of the health facility. Government is now preparing to introduce this service in six selected pilot districts.

Objective: This survey was carried out to assess the functioning of existing abortion services in 12 Government approved CAC sites of three districts.

Materials and methods: Direct observation of the functioning of these centers, assessment of physical facilities and service provider's skill was done. At the same time service provider's attitude and knowledge on CAC service and other abortion services were also assessed through semi structured interviews. Quality of record keeping and the feasibility of initiating the medical abortion service in these sites were also studied.

Result: Number of listed centers in six pilot districts was twenty nine. Study districts have 16 listed centers. Visited sites were twelve; four managed by Government and eight by non government organizations.

Thirty three thousand nine hundred and twenty women have availed this service so far: only $4.76 \%$ of them received service from Government facilities. Marie Stopes International (MSI) topped the list in providing service to the maximum number of clients (75.64\%) and Family planning association of Nepal (FPAN) was the second. MSI centre was also first to initiate the service. Government facilities provide 24 hours service unlike private facilities which are open only up to $5.00 \mathrm{pm}$. Cost for the service varies from rupees 900/- to rupees 1365/- and is cheaper at Government facilities. Private sectors have separate setups and Government have allocated some space within their already existing infrastructure for $\mathrm{CAC}$ service. Private sectors were better in providing the information to public about the availability of service. There were total 20 trained service providers for first trimester abortion service. They are more at Government facilities. They seem to be positive to CAC service and had good knowledge and skill of service delivery. Complications were not recorded at most of the sites. Pain management and infection prevention practice needs improvement at the Government sites. All the sites had identified their referral sites and had one or the other arrangement for referral.

Conclusion: CAC service has become accessible and affordable to Nepalese women even at peripheral level. CAC sites are functioning well. Initiation of medical abortion and second trimester abortion services at these sites are feasible and would expand the option and choices available.
\end{abstract}

Key words: Comprehensive abortion care (CAC), medical abortion, unsafe abortion,

U nsafe abortion is the second most important cause of maternal death not only in Nepal but also in most of the developing countries and accounts for $13 \%$ of the global maternal death ${ }^{1}$.

Abortion has been legalized in Nepal since September 2002 after many years of intensive research, advocacy and lobbying ${ }^{2}$. The procedural order was passed in $2003^{2}$ and under this law abortion service was provided to the clients in a comprehensive manner and is popularly known as CAC (Comprehensive Abortion
Care) service. Nepal Government has started providing safe abortion services through its health facilities since 2004. According to the procedural order, both service providers and the facility providing this service must be approved by and listed to Family Health Division,

Correspondence

Dr. Chanda Karki

Associate Professor,

Department of Obstetrics and Gynecology,

Kathmandu Medical College

E-mail: chanda_karki@hotmail.com 
Ministry of Health. Till date more than 500 service providers and 75 health facilities (at least one in each district) have already been listed for this purpose. Family Health Division has also designed and developed a logo for CAC service to help the clients to identify safe abortion service sites.

Nepal Government, through Ministry of Health has, prioritized the national safe abortion program and is working with many government and non government organizations. Its partners are Marie Stopes International (MSI), Family Planning Association of Nepal (FPAN) and others. These organizations are providing safe abortion service in the country through surgical procedure only. Clients do not have other choice as medical abortion services are not provided through any of these health facilities till date. Evidences show that medical methods of abortion are also safe and effective ${ }^{3}$.

Two studies done on acceptability and feasibility of medical abortion in Nepal have shown good success rate, negligible side effects and good acceptability and feasibility in the country ${ }^{4,5}$.

Based on these studies and other global evidences, Nepal Government is also planning to introduce the medical abortion service to broaden the choice available to Nepalese women. In this process a high level task force has been formed, national strategy has already been developed, drugs have been registered, development of training manuals and Information, Education and Communication (IEC) materials have been accomplished and one batch of trainers has already been prepared. Nepal Government is now ready to initiate this service in six pilot districts (Jhapa, Chitwan, Kailali, Dhading, Tanahu and Surkhet) of Nepal.

\section{Objectives}

\section{General Objective}

To do a baseline survey on functioning of existing abortion services in Government approved CAC centers in three pilot districts of Nepal.

\section{Specific objectives}

1. To conduct field observation at selected CAC sites to assess the quality of care of service at both Government and Non Government organization managed centers

2. To examine the functioning of CAC centers in terms of

i. Year and cost of service

ii. Location of service site, adequacy of space, equipment and essential drugs iii. Working hour, case load and referral pattern

iv. Information about the availability of services

v. Number and level of trained service providers

vi. Availability of counselling services and status of confidentiality

vii. Drugs used to minimize pain and infection

viii. Complication records, its management or referral

ix. Other Reproductive Health services offered from this centre

x. Range of Family Planning (FP) services provided

xi. Recording and reporting system

3. To assess service provider's attitude towards abortion and CAC Service, knowledge about availability and quality of the service provided and about medical abortion.

4. To assess the feasibility to initiate the medical abortion service in these sites

\section{Materials and methods}

A baseline survey on functioning of existing abortion services in Government approved CAC centers in three out of six pilot districts was carried out. Selected districts were Dhading, Chitwan and Jhapa. These three districts have 16 listed centers. With the initiative and support from CREHPA (centre for research on Environment, Health and population activities), twelve out of these sixteen sites were visited during the working hour. Two to three nights were spent in each district from $29^{\text {th }}$ Bhadra 2065 to $11^{\text {th }}$ Asoj 2065. These sites were Dhadingbesi Hospital, Bharatpur District Hospital, Mechi Zonal Hospital, Dhulabari Priamry Health Centre, MSI Gajuri, Sunaulo Bhabisya Nepal Narayanghat, MSI Narayanghat, Adarsha Nari Bikas Kendra Narayanghat, FPAN Bharatpur, MSI Damak, MSI Birtamod and FPAN Charali.

In each CAC centres direct observation of the functioning of the CAC centres, assessment of physical facilities and trained human resources was carried out. Facility records were checked to find out the year of initiation of service, cost of service, case load, number and nature of complications with their management and referral, recording and reporting system. An enquiry with the administration was made to find out if these facilities have Comprehensive Emergency Obstetric Care service, transportation facility for referring the client and blood transfusion facilities. Availability of functional MVA sets, canulas and essential medicines were checked at the procedure room as well as in the store. Information on working days and hours, source of the clients, number of complications, availability of second trimester and medical abortion service was 
obtained from the Health care staff in the facility. For this purpose a pre prepared questionnaire form was utilized.

Information on service providers attitude towards abortion and CAC service, mechanism and quality of CAC service delivery, reasons why client chose their site, number and nature of complications, identified referral centers, memorandum of understanding (MOU) signed for referral, ways of increasing case load and other services provided from their centre were obtained through semi structured interviews with one service provider in each health facility. These findings were compared with the findings obtained through direct observation of the site. They were also asked about whether the introduction of medical abortion service to their facility will be helpful to increase the client load of their facility.

At each site CAC procedure was observed to assess service providers skill on counselling, pain management, procedure, and recovery care using the standard checklist developed for this procedure.

\section{Results}

Number of listed centres providing CAC service in six pilot districts was twenty nine. This is about six percent of the total sites in the country. Dhading, Chitwan and Jhapa districts have 16 listed centers. Seven centers (44\%) were managed by Government, 5 centers by MSI, 2 centres by FPAN and remaining 2 by others (adarsha Nari Bikas Kendra-1 and Sunaulo Bhabisya Nepal-1). It was clearly seen that more than $50 \%$ of these sites were run and managed by non government organizations. Results presented are from twelve sites that were visited. As shown in table 1, four of these sites were managed by Government and eight by non government organizations.

\section{Year, cost and time schedule of service}

As shown in table 2, MSI centre was the first organization to initiate this service. Government facilities have been providing the service for last two to four years and the non government sectors for last one to five and half years. All the service centres are open six days a week but only the government facilities provide 24 hours service. Private sites are closed after 4-5 pm. Services at Government sites are supposed to start at $10.00 \mathrm{am}$, but it was observed that the clients had to wait for one to three hours to get the service at almost all the government sites whereas at private facilities the clients received warm welcome, prompt response and swift service.

Cost for the service is cheaper at Governmental facilities, ranging from Nrs $900-1000$ but the rates at other facilities are also not very high. FPAN's charges are similar to the Government facility. MSI centres have a fixed cost of Nrs 1350 at all their clinics and other sites charge in between Nrs 1285 to 1365 .

\section{Location of service site}

MSI and other centres like Sunaulo Bhabisya and Adarsha Nari bikas Kendra are primarily developed to provide CAC service and therefore have a very good setup for it. These facilities have a nice reception counter and a comfortable waiting area with TV displayed all the time. There is always a person ready to attend the clients as soon as they arrive unlike the Government facilities where clients do not know where to go for this service. They have separate rooms for counselling, screening, procedure, recovery and sterilization.

FPAN centres also have developed good setups for CAC service and are almost similar to MSI centres. Government set ups have allocated some space for this service within their already existing infrastructure and are providing the multispecialty services too.

Dhardingbesi and Mechi Zonal Hospital have identified one room inside the labour room for this purpose. There is no separate place for counselling or for comfortable lying down after the procedure. This was found to be a barrier to some extent in maintaining confidentiality. Counselling was very much compromised as there is neither a place nor a separate counsellor for counselling and the doctors do not have time for adequate counselling as they have to provide other services too.

Bharatpur hospital has identified a separate place for CAC service but this space at the moment is utilized as operation theatre and the CAC service is provided at a place identified for neonatal intensive care unit.

Primary Health Centre (PHC) Dhulabari has one room allocated for $\mathrm{CAC}$ and this room was locked during two visits made to this centre, key being with the doctor who had gone to attend some meeting.

\section{Confidentiality}

Because of the good setup and separate infrastructure in the private facilities, confidentiality was very well maintained whereas in the Government facilities confidentiality was compromised because of the lack of separate space for counselling and recovery and due to few trained counsellor.

\section{Equipment and essential drugs}

They are found to be adequate at all facilities. All the sites had good stocks of functioning MVA sets, canulas of all the sizes and emergency drugs. Oxygen cylinders, mask and bag were available at all the sites. 


\section{Case load}

Thirty-three thousand nine hundred and twenty women had received CAC service from these sites so far. Only $4.76 \%$ of women received the service from the Government facilities. MSI topped the list in providing service to the maximum number of clients $(75.64 \%)$; FPAN was second with $13.05 \%$ of the total clients and $6.53 \%$ of the clients were served by newly opened private sites like Sunaulo Bhabisya and Adarsha Nari Bikas Kendra, Narayanghat. Out of the Government sites case load at Mechi Zonal Hospital and PHC, Dhulabari was very low whereas Dhardingbesi hospital and Bharatpur Hospital has better client flow. Number of clients at most of these sites seems to be increasing every year.

\section{Client Source}

Non Governmental sites received clients mostly from medical shops, female community health volunteers (FCHVs), Health workers, social organizations and satisfied clients. Good number of clients was referred by the satisfied clients in NGO managed sites. This category of referral was totally missing in government facilities. All the sites had clients coming on their own because the facility was nearby to their residence.

\section{Information about the service}

Information about the availability of service, time schedule and its cost is provided to the clients and general public by a notice board or banner at the visible area of the facility.

Only one governmental site (Bharatpur Hospital) had such information displayed on the wall of the Hospital on a flex. This flex had a logo of CAC developed by Ministry of Health.

All the private facilities had a good sized and colorful boards displayed at a visible area of the facility which contained information on cost as well as day and time of the service. MSI and some of the centres had their own logo on the board. They were not aware about existence of Government designed logo for CAC. Only three private centers had CAC logo on their board.

Some of the service sites like Dhading besi Hospital, FPAN Bharatpur and PHC Dhulabari had service fee written on the inside wall of the Hospital. CAC logo was kept inside the CAC room at Dhadingbesi Hospital and MSI Damak.

\section{Trained service providers}

There were 20 trained service providers providing first trimester abortion services at these 12 sites. Most of the service providers are MBBS doctors. Two of them were nurses and one was obstetrician and Gynecologist.
None of them were trained for second trimester abortion and only one of the providers at Mechi Zonal Hospital had recently received training on medical abortion. Number of trained service providers seems to be more at Governmental facilities. They ranged from one to seven in numbers. Government facilities also had two nurses (one at Dhadingbesi and the other at Bharatpur Hospital) trained to provide CAC service and four nurses trained to assist the CAC. Private centres had one doctor service provider at each site and six nurses (altogether) were trained as CAC assistants.

\section{Counselling}

Counselling part was better at private facilities. They had a separate place for counselling and also had a trained counsellor appointed for this purpose. Most of the government owned sites neither had a separate place nor a separate counsellor for counselling.

\section{Complications}

Complications were recorded only at MSI, Birtamod and the record showed there were $34(1.98 \%)$ cases of minor complications in the year 2007. All of them had come either with incomplete abortion or with complaints of slight vaginal bleeding. Repeat MVA was required for less than $1 \%$. All other sites did not have complication records and verbally said there were none of the cases coming with complications.

\section{Referral sites}

Dhadingbesi hospital and MSI, Gajuri had identified Prasuti griha (90 km distance), Narayanghat centres like Sunaulo Bhabisya, MSI, Adarsha Nari Kendra had identified Narayani Samudaic Hospital (2 km) and Bharatpur Hospital (3 km), Mechi Zonal Hospital has identified Koshi Zonal Hospital (80 km), MSI Damak, Birtamod and FPAN Charali has identified Amda Hospital Kharkhare $(2-30 \mathrm{~km})$ and PHC Dhulabari has identified Mechi Zonal Hospital $(10 \mathrm{~km})$ as their referral sites. These sites did not have any records of patient referrals so far.

\section{Pain and infection management}

Regarding the use of drugs to minimize pain and infection, antibiotics were routinely prescribed at all the sites but pain management was not taken seriously by most of the sites. Oral analgesics and sedatives either were not prescribed or not given on time. Clients were taken to the procedure table immediately after giving them oral analgesics. Most of the service providers had a tendency to omit Para cervical block on the ground that it makes the field messy with bleeding and it is time consuming. Infection prevention practice in terms of sterilization techniques, instrument cleanliness, surface cleanliness and waste management needed lot of improvement at Government sites in comparison to 
private sites. Dhadingbesi hospital has been sterilizing the instrument and gloves in Momo pot, Mechi Zonal Hospital does not have a functioning incinerator and PHC Dhulabari does not seem to involve other staffs for CAC functioning. Infection prevention practice is excellent at private sites. They have excellent autoclave facility, surface cleanliness and waste management system. They have been practicing each steps of Infection Prevention (IP) guideline.

\section{Other services}

As has already been mentioned basic and comprehensive emergency obstetric care services and Family planning services are offered from most of the governmental centres but private sectors are providing only CAC and Family planning services. Dhadingbesi Hospital provides intra uterine contraceptive devices (IUCD), Norplant, Oral Contraceptive Pills (OCPs), condoms, Depot provera and Vasectomy service. Bharatpur Hospital provides all permanent and temporary family planning services. Mechi Zonal Hospital and PHC Dhulabari does not provide permanent and Norplant services. Private sites are providing full range of FP services to a good number of clients. None of these centres were providing second trimester abortion and medical abortion services. They seem to refuse the clients of higher gestation in first trimester and also second trimester.

\section{Recording and Reporting}

Recording and reporting system at all the sites except PHC, Dhulabari seemed to be satisfactory but again it is found to be better at private sites. All of them are using Health Management Information System (HMIS) 11 register to record the data. All of them are collecting FCHV referral cards and all of them are reporting their statistics to Family Health Division of Ministry of Health regularly. MSI centres had best record keeping system. Besides their records on registers and computers, they used to display their records on the board hanged on the wall on daily, monthly and yearly basis. Performance improvement registers are not used by any sites except Mechi Zonal Hospital.

\section{Service Provider's outlook}

Twelve service providers from 12 CAC sites were interviewed. Four of them were female service providers and the rest were male. Duration of their service at these sites varied from three months to five years. They seem to spend around four to seven hours of their time for CAC service. At most of the Government sites, service provider does not spend more than two to three hours at CAC room. Most of their time was spent in OPD which they counted to have spent for CAC.
As shown in Table 3, Service providers of all the sites were very much positive to provide CAC service, had good knowledge about the client load, its increasing or decreasing pattern and maximum capacity of their site. They also seemed to be aware about the referral pattern of the clients. Service Providers from Dhadingbesi and Mechi Zonal hospital, FPAN centres, Sunaulo Bhabisya, Narayanghat and Adarsha Nari Bikas Kendra were not aware if any memorandum of understanding (MOU) was signed with referral hospitals.

They believed that there might be further increase in the case load if more advocacy is done; service is improved and cost is reduced. Service providers at Government facilities were of opinion that the load of clients will increase if incentive was provided to the persons referring the clients to their sites as done in other private facilities and if the networking to the referral sites is strengthened.

Regarding the complications of CAC, most of the service providers stated that there were two to three cases coming every month with CAC complications which was not justified by their records.

Service providers from all the sites were aware about the availability and popularity of family planning and other services. They also knew very well the reasons for which clients chose their site for CAC and FP services.

As far as the skill of the CAC procedure was concerned, all the service providers could perform CAC very well but service providers of the Government sites probably need to give more time for counselling, pain management and recovery care (Table-4).

\section{Feasibility to initiate medical abortion services}

Medical abortion service is not available at any of these sites but Service Providers of all the sites had heard about it. All of them were of opinion that provision of medical abortion service in their site will help to increase the number of clients coming to their site. The logic behind this was that the medical abortion is an easy and noninvasive method, clients frequently come to ask for it, public easily accepts new changes, it does not cause as much pain as surgical method, more privacy is maintained, more confidentiality is obtained and even nurses will be able to provide this service.

This service was feasible for these sites because all of them had the back up service for CAC, for complication management and blood transfusion. Referral sites for complication management are within the distance of $2 \mathrm{~km}$ and transportation facility could be organized from Government and FPAN sites. 
Table 1: Government and NGO managed CAC site list

\begin{tabular}{|c|c|c|c|c|}
\hline Sites & $\mathbf{1}$ & $\mathbf{2}$ & $\mathbf{3}$ & $\mathbf{4}$ \\
\hline Governmental & $\begin{array}{c}\text { Dhardingbesi } \\
\text { Hospital }\end{array}$ & $\begin{array}{c}\text { Bharatpur district } \\
\text { Hospital }\end{array}$ & $\begin{array}{c}\text { Mechi Anchal } \\
\text { Hospital }\end{array}$ & PHC dhulabari \\
\hline Non Governmental organizations & Gajuri & Narayanghat & Damak & Birtamod \\
\hline MSI & Bharatpur & Charali & & \\
\hline FPAN & $\begin{array}{c}\text { Adarsha Nari } \\
\text { Bikash Kendra, } \\
\text { Narayanghat } \\
\text { Others }\end{array}$ & Narayanghat & & \\
\hline
\end{tabular}

Table 2: Functioning of the CAC service

\begin{tabular}{|c|c|c|c|c|}
\hline & Government & MSI & FPAN & Others \\
\hline Year of service & $2-4$ years & $1-5.5$ years & $3-4$ years & $1-3$ years \\
\hline Days of service per week & 6 & 6 & 6 & 6 \\
\hline 24 hours service & Yes & No & No & No \\
\hline Cost of service & $900-1000 /-$ & $1350 /-$ & $1000-1080 /-$ & $1285-1365 /-$ \\
\hline Separate CAC unit & No & Yes & Yes & Yes \\
\hline Number of rooms assigned for CAC & $1-4$ & 6 & $4-6$ & $4-6$ \\
\hline Confidentiality & $\begin{array}{l}\text { Tried but needs } \\
\text { improvement }\end{array}$ & Maintained & Maintained & Maintained \\
\hline Equipments and drugs & Adequate & Adequate & Adequate & Adequate \\
\hline Total clients served so far & 1616 & 25,659 & 4,428 & 2,217 \\
\hline Clients source & $\begin{array}{c}\text { Nearby areas on } \\
\text { their own, Female } \\
\text { community Health } \\
\text { Volunteers (FCHV), } \\
\text { hospital staffs, medical } \\
\text { shops }\end{array}$ & $\begin{array}{l}\text { Nearby areas on their } \\
\text { own, FCHV, facility } \\
\text { staffs, medical shops, } \\
\text { radio listeners, satisfied } \\
\text { clients }\end{array}$ & $\begin{array}{l}\text { Nearby areas on their } \\
\text { own, FCHV, facility } \\
\text { staffs, medical shops, } \\
\text { radio listeners, satisfied } \\
\text { clients }\end{array}$ & $\begin{array}{l}\text { Nearby areas on their } \\
\text { own, FCHV, facility } \\
\text { staffs, medical shops, } \\
\text { radio listeners, satisfied } \\
\text { clients }\end{array}$ \\
\hline Signboard in visible area & Present at only one site & Present & Present & Present \\
\hline CAC Logo & Present at only one site & Present at only one site & Present at one site & Present at one site \\
\hline CAC trained SP & $1-7$ & 1 & 1 & 1 \\
\hline Counselors & $\begin{array}{l}\text { Present only at one site } \\
\text { (Bharatpur Hospital) }\end{array}$ & $\begin{array}{c}\text { Present at } 3 \text { sites. } \\
\text { Absent at one site } \\
\text { (Gajuri) }\end{array}$ & Present at both sites & $\begin{array}{l}\text { Present at Sunaulo } \\
\text { Bhabisya only }\end{array}$ \\
\hline CAC Complications & Not recorded & $\begin{array}{c}\text { Recorded at only one } \\
\text { site }\end{array}$ & Not recorded & Not recorded \\
\hline Pain management & $\begin{array}{l}\text { Analgesics and or } \\
\text { sedative not given half } \\
\text { an hour before the } \\
\text { procedure/ Paracervical } \\
\text { block only practiced at } \\
\text { Bharatpur hospital }\end{array}$ & $\begin{array}{c}\text { Analgesics and } \\
\text { or sedative given } \\
\text { half an hour before } \\
\text { the procedure but } \\
\text { Paracervical block not } \\
\text { routinely practiced }\end{array}$ & $\begin{array}{l}\text { Analgesics and or } \\
\text { sedative not given half } \\
\text { an hour before the } \\
\text { procedure/ Paracervical } \\
\text { block only practiced at } \\
\text { FPAN Bharatpur }\end{array}$ & Not taken seriously \\
\hline Antibiotics & $\begin{array}{l}\text { Doxycycline routinely } \\
\text { prescribed }\end{array}$ & $\begin{array}{c}\text { Doxycycline routinely } \\
\text { prescribed }\end{array}$ & $\begin{array}{l}\text { Doxycycline routinely } \\
\text { prescribed }\end{array}$ & $\begin{array}{c}\text { Doxycycline routinely } \\
\text { prescribed }\end{array}$ \\
\hline IP practice & Needs improvement & Excellent & Very good & Good \\
\hline BEOC/CEOC Site* & Yes & No & No & No \\
\hline $\begin{array}{l}\text { Second Trimester Abortion and Medical } \\
\text { Abortion service }\end{array}$ & Not available & Not available & Not available & Not available \\
\hline FP Service & Yes & Yes & Yes & Yes \\
\hline Record keeping & $\begin{array}{l}\text { Yes but needs } \\
\text { improvement }\end{array}$ & Excellent & Good & Good \\
\hline $\begin{array}{l}\text { Records displayed daily, monthly or } \\
\text { yearly }\end{array}$ & No & Yes & No & No \\
\hline
\end{tabular}

* BEOC/CEOC: Basic essential obstetric care/Comprehensive essential Obstetric care 
Table 3: Service provider's knowledge and attitude towards abortion and CAC Service, on availability and quality of the service provided from their centre

\begin{tabular}{|c|c|c|c|c|c|c|c|c|}
\hline \multirow{2}{*}{ Sites } & & \multicolumn{7}{|c|}{ Knowledge about } \\
\cline { 3 - 9 } & $\begin{array}{c}\text { Attitude } \\
\text { towards } \\
\text { CAC }\end{array}$ & $\begin{array}{c}\text { Case load } \\
\text { and time } \\
\text { schedule }\end{array}$ & $\begin{array}{c}\text { Number and } \\
\text { referral of } \\
\text { complication }\end{array}$ & $\begin{array}{c}\text { MOU } \\
\text { signed } \\
\text { with } \\
\text { referral } \\
\text { site }\end{array}$ & $\begin{array}{c}\text { Reason } \\
\text { for } \\
\text { choosing } \\
\text { the } \\
\text { site for } \\
\text { service }\end{array}$ & $\begin{array}{c}\text { Increasing } \\
\text { or } \\
\text { decreasing } \\
\text { pattern of } \\
\text { clients }\end{array}$ & $\begin{array}{c}\text { How to } \\
\text { increase } \\
\text { the } \\
\text { number } \\
\text { of clients }\end{array}$ & $\begin{array}{c}\text { Available } \\
\text { services } \\
\text { at the } \\
\text { site }\end{array}$ \\
\hline Government & Positive & Aware & $\begin{array}{c}\text { Yes but not } \\
\text { recorded }\end{array}$ & No & Yes & Yes & Yes & Yes \\
\hline MSI & Positive & Aware & $\begin{array}{c}\text { Yes, recorded at } \\
\text { only one site }\end{array}$ & Yes & Yes & Yes & Yes & Yes \\
\hline FPAN & Positive & Aware & $\begin{array}{c}\text { Yes but not } \\
\text { recorded }\end{array}$ & No & Yes & Yes & Yes & Yes \\
\hline Others & Positive & Aware & No & No & Yes & No & Yes & Yes \\
\hline
\end{tabular}

Table 4: Skill assessment

\begin{tabular}{|c|c|c|c|c|c|}
\hline \multirow{2}{*}{ Sites } & \multicolumn{5}{|c|}{ Skill Assessment } \\
\cline { 2 - 6 } & Cases observed & Counseling & Preoperative care & Procedural skill & Recovery care \\
\hline Government & 3 & Poor & Satisfactory & Very Good & Satisfactory \\
\hline MSI & 3 & Excellent & Excellent & Excellent & Excellent \\
\hline FPAN & 1 & Excellent & Good & Excellent & Excellent \\
\hline Others & 1 & Good & Good & Good & Excellent \\
\hline
\end{tabular}

Table 5: Requirements to initiate Medical abortion services

\begin{tabular}{|c|c|c|c|c|}
\hline Back up service for CAC & Government & MSI & FPAN & Others \\
\hline $\begin{array}{c}\text { Back up service for } \\
\text { complication management }\end{array}$ & Present & $\begin{array}{c}\text { Present } \\
\text { identified its } \\
\text { referral site }\end{array}$ & $\begin{array}{c}\text { Absent but has } \\
\text { identified its } \\
\text { referral site }\end{array}$ & $\begin{array}{c}\text { Absent but sites } \\
\text { very close to } \\
\text { referral sites }\end{array}$ \\
\hline Referral site & Not required & $\begin{array}{c}\text { Within two hours } \\
\text { of travel }\end{array}$ & $\begin{array}{c}\text { Within two hours } \\
\text { of travel }\end{array}$ & $\begin{array}{c}\text { Within 10-20 } \\
\text { minutes of travel }\end{array}$ \\
\hline Hospital transportation & Available & Capable to arrange & Available & Capable to arrange \\
\hline Blood transfusion facility & Available & $\begin{array}{c}\text { Not available but } \\
\text { is within reach }\end{array}$ & Not available & Not available \\
\hline
\end{tabular}

\section{Discussion}

Till few years ago, it was not possible for a woman to get a safe abortion service without going to a gynaecologist in an urban area and without spending a good amount of money for it and a hospital based study showed that even in urban areas many abortion service providers were often untrained and unknowledgeable about the unsafe, unhygienic and sometimes fatal nature of their practices $^{6}$. The situation can only be expected to be much worse in rural areas considering very high rate of illiteracy, scarcity of trained service providers and limited access to the health facilities.
Now after the liberalization of the law it is so nice to see that there are plenty of organizations providing this service in various districts of the country. Most of the sites had started their service in the year 2004. The first ever comprehensive abortion care service was started at the maternity Hospital, Kathmandu in March 2004,8 and now in less than four years time this service is being provided from the listed sites at 75 districts of Nepal with more than 500 listed service providers. More and more of the private organizations are coming forward to provide this service. Till date Safe abortion services 
are being provided only by surgical means. It was good to see that till date these 12 centres have provided this service to about 33,917 women.

Non government organizations seem to be better both quantitatively and qualitatively but governmental organizations are open for 24 hours and are the best sites for providing the good back up service for managing the complications.

Ministry of Health through Family Health Division and TCIC has been trying not only to standardize the procedure but also to minimize the costs as a result of which cost of the procedure has come down substantially and is found to be more or less uniform at all the sites.

Only $5 \%$ of the clients have received the service from the Government sites. Probably Government sites needs to improve in terms of physical infrastructure and human resource. Various policies and programs need to be introduced on high priority basis to increase the client flow to the government facilities. Private sectors are serving a huge number of clients because of their focused service at their sites with good physical infrastructure and because of the scheme where they provide certain monetary incentive for referring the clients to their sites.

Government has designed a logo to make it easier for the clients to identify the sites providing safe abortion service. This information needs to be disseminated to all the health facilities and the general public nationwide.

It was really interesting to note that Government sites with maximum numbers of trained service providers were serving a very minimum number of people. This may be because the service providers are busy in providing other services in the health facility. Mid level service provider's performance in the record was found to be excellent. Though they were on long leave at the time of visit, records witnessed that they had performed CAC service to a good number of clients.

Most of the sites are not aware of the presence of Government designed performance improvement register to identify the barriers or difficulties in service provision and therefore is not being used in most of the sites. This is probably the reason why there is no reporting or discussion on the issues to be solved to improve the service on continuous basis.

As the service for first trimester abortion is well established at almost all of these sites and the backup services are available to manage the complications, medical abortion service should also be initiated through these sites as soon as possible. At the same time service providers should also be trained to provide second trimester abortion service so that clients can have full range of abortion services available at all these sites.

\section{Conclusion}

CAC service has become accessible and affordable to Nepalese women even at peripheral level. CAC sites are functioning well. Most of the clients received service from NGO run sites. The Government facility service providers and facility managers need to clarify roles, responsibilities and values regarding providing service to clients in need. Their unsympathetic attitude towards client's needs and attitude seems to be the important reason for a very small case load. Government facilities have to provide multidisciplinary services and therefore CAC service may not get the high priority for the managers but strengthening of CAC services and Comprehensive Essential Obstetric Care (CEOC) service at the governmental site is very important because people have faith in government facilities and they have to play an important role in providing back up service for the non government organization run service sites. The private sites which open only from nine to five pm need to coordinate with Government sites for referral.

The information that these NGO run CAC sites open only up to $5.00 \mathrm{pm}$ and the clients need to go to identified referral site to seek the service at odd hours; needs to be provided to the clients clearly at the very beginning.

Ministry ofHealth should have programs for continuously training the service providers and expanding the service to each and every corner of the country, for follow up and monitoring the services of both Government and non government organizations.

The important factor that should be considered by the Government is that Medical abortion service with Mifepristone and Misoprostol should also be offered to the clients through these sites. This would expand the options and choices available and make abortion more accessible to women and allow services to make CAC service available at lower levels of care. This service can be delivered to the clients even with the help of nurse and non-specialist doctors. Very minor percentage of these clients might require back up facility of $\mathrm{CAC}$ and PAC service. To make the medical abortion service effective, availability of the drugs needs to be ensured, human resource needs to be trained and for the scaling up medication abortion curriculum needs to be incorporated into general CAC training.

Some of the service sites have a tendency to refuse the clients with higher gestation (usually 10-12 weeks size). This has deprived the clients of their rights to 
safe and legal abortion up to 12 weeks of gestation. Therefore Service providers should also be provided with additional training on Manual Vacuum Aspiration (MVA) procedure for higher uterine gestation to build their confidence to handle high gestational cases. There are certain clients who do need services beyond 12 weeks and this need can not be served by any of these sites. Therefore service providers should also be trained on second trimester services and government needs to develop more centres capable of providing such services. Strengthening of the family planning service should be continuously in place on priority basis to minimize the incidence of unwanted pregnancy.

Lastly, it is our duty to raise awareness among the population of the legality and availability of the services. Each newly listed clinic should be responsible for developing a communication plan that informs the local population of service availability. The Government should work closely with legal expert, right based organizations and community networks to expand information, education and communication (IEC) to women.

\section{Acknowledgement}

This survey was possible only with the cooperation of individual CAC centres. I am grateful to all the District Health officers, Medical Superintendents, service providers and staffs of all the sites in three districts.

I am thankful to Family Health Division and Technical committee for implementation of safe abortion care (TCIC) for their cooperation and support to carry out this survey.

My special thanks go to Mr. Ananda Tamang for having faith in me to carry out this survey and to Centre for Research on Environment Health and Population Activities, Nepal for funding this survey.

\section{References}

1. Ministry of Health Nepal. National maternal mortality and morbidity study. Kathmandu, Nepal: Ministry of Health; 1998.

2. Forum for woman, law and development (FWLD). Struggles to legalize abortion in Nepal and challenges ahead. Kathmandu, Nepal: FWLD; 2003.

3. World Health Organization (WHO). Safe abortion: Technical and policy guidance for Health systems. Geneva: WHO; 2003.

4. Karki C, Pokharel H, Kuswaha A, Manandhar D, Bracken H, Beverly W. Acceptability and feasibility of medical abortion in Nepal. Submitted for publication to International Journal of Obstetrics and Gynaecology in 2008.

5. Shrivastava V. Safety, efficacy and acceptability of medical abortion with Mifepristone and Misoprostol in Nepalese women. Nepal Journal of Obstetricians and Gynaecologists 2007; NovDec (2):54-8.

6. Thapa PJ, Thapa S, Shrestha N. A Hospital based study of abortion in Nepal. Studies in family planning 1992;23(5):311-8.

7. Family Health Division, TCIC, CREHPA, FWLD, Ipas, PATH. Woman's right to choose: Partnerships for safe abortion in Nepal. Bird C ed. Kathmandu: FWLD; 2005.

8. Family Health Division, CREHPA, Ipas. Nepal Comprehensive abortion care, National facility based abortion study. Kathmandu: Family Health Division, CREHPA and Ipas; December 2006. 